\title{
Concordance in the Health Behaviors of Couples by Age: A Cross-sectional Study
}

\author{
Seungmin Jeong, Sung-il Cho \\ Department of Preventive Medicine, Graduate School of Public Health, Seoul National University, Seoul, Korea
}

Objectives: To investigate concordance in the health behaviors of women and their partners according to age and to investigate whether there was a stronger correlation between the health behaviors of housewives and those of their partners than between the health behaviors of non-housewives and those of their partners.

Methods: We used data obtained from women participants in the 2015 Korea Community Health Survey who were living with their partners. The outcome variables were 4 health behaviors: smoking, drinking, eating salty food, and physical activity. The main independent variables were the partners' corresponding health behaviors. We categorized age into 4 groups (19-29, 30-49, 50-64, and $\geq$ 65 years) and utilized multivariate logistic regression analysis, stratifying by age group. Another logistic regression analysis was stratified by whether the participant identified as a housewife.

Results: Data from 64971 women older than 18 years of age were analyzed. Of the 4 health behaviors, the risk of smoking (adjusted odds ratio [aOR], 4.65; 95\% confidence interval [Cl], 3.93 to 5.49) was highest when the participant's partner was also a smoker. Similar results were found for an inactive lifestyle (aOR, 2.56; $95 \% \mathrm{Cl}, 2.45$ to 2.66), eating salty food (aOR, 2.48; 95\% Cl, 2.36 to 2.62); and excessive drinking (aOR, 1.89; $95 \% \mathrm{Cl}, 1.80$ to 1.98). In comparison to non-housewives, housewives had higher odds of eating salty food. Conclusions: The health behaviors of women were positively correlated with those of their partners. The magnitude of the concordance differed by age group.

Key words: Women's health, Health behavior, Spouses, Korea

\section{INTRODUCTION}

Health behaviors, such as smoking, drinking, eating salty foods, and physical activity, have significant effects on health status and life expectancy because they are primary causes of

Received: September 6, 2017 Accepted: November 15, 2017

Corresponding author: Sung-il Cho, MD, ScD

Department of Preventive Medicine, Graduate School of Public Health,

Seoul National University, 1 Gwanak-ro, Gwanak-gu, Seoul 08826, Korea E-mail: scho@snu.ac.kr

This is an Open Access article distributed under the terms of the Creative Commons Attribution Non-Commercial License (http://creativecommons.org/licenses/bync/4.0//) which permits unrestricted non-commercial use, distribution, and reproduction in any medium, provided the original work is properly cited. chronic diseases [1-3]. Factors on the interpersonal, community, and individual (e.g., genetics and personal characteristics) levels are considered to be important influences on health behaviors [4]. Indeed, interactions with the environment and culture of a community can affect an individual's lifestyle in direct and indirect ways [5].

Analyses on the level of the household, the smallest family unit of a community, have frequently been performed to investigate the effects of interpersonal interactions on personal health behaviors $[6,7]$. Couples and siblings are particularly useful in this regard because they have very close relationships and are usually close in age. However, unlike siblings, couples do not share genetic characteristics. Therefore, a focus 
on couples enables the effects of interpersonal interactions on health behaviors to be investigated without having to account for genetic influences $[8,9]$.

Previous studies have found that health behaviors are affected by spouses [8,10-13]. However, age-stratified studies on this subject have not been performed. We assumed that associations between the health behaviors of partners (i.e., intra-couple associations) would differ across age groups for many reasons, including differences according to the age-cohort effect, the duration of the partnership, and so on. We also hypothesized that stronger correlations would be found for housewives than for non-housewives. Non-housewives have a larger social network than housewives, whereas housewives spend more time at home, meaning that they spend more time with their partners than non-housewives. However, there has been little investigation of this issue.

In this study, we assessed the influence of partners' behaviors on the health behaviors of women stratified by age group. We also investigated whether there was a greater spousal influence on the behaviors of housewives in comparison to nonhousewives.

\section{METHODS}

We used data from the 2015 Korea Community Health Survey (KCHS). The KCHS has been conducted nationwide since 2008. It aims to produce health statistics to inform the development and evaluation of regional health policy in Korea. This survey is organized by the Korean Centers for Diseases Control and Prevention with the support of each county's public health center and 35 universities. The targets of this survey are adults at least 19 years of age. The central statistics team of this survey develops the sampling frame using official residential information, and the public health centers and universities confirm the households in the sample. The mean number of participants in each county is 900 . Trained interviewers visit the sample households to collect information through a structured individual face-to-face interview. Individual-level information includes health habits, medical service use, quality of life, and so on. Household-level information includes monthly household income, residence type, and so on. All interview data are processed using a computer program. Many previous reports have been published using the results of this survey [14-16].

In this study, we included women living with their partners.
The KCHS is anonymous, but we were able to identify couples using household identification (ID) number, sex, and marital status. In this process, same-sex couples were inevitably excluded. We also excluded households that included more than 1 couple because of the possibility of mismatching members of the couples. We defined a couple as 2 opposite-sex individuals who were cohabiting with or without being legally married.

Our outcome variables were 4 health behaviors: smoking, drinking, eating salty foods, and physical activity. We categorized respondents as non-smokers, ex-smokers, and current smokers. We categorized alcohol consumption into 3 groups (no drinking, moderate drinking, and excessive drinking) according to the World Health Organization (WHO) definition of excessive drinking in women as the consumption of over $20 \mathrm{~g}$ of pure alcohol at once [17]. We categorized eating salty foods according to responses to the following question: "Which of the following descriptions is most appropriate for you when you eat?" We categorized physical activity by intensity, duration, and frequency. Participants who responded that they did not engage in any high-impact or moderate-impact activity in a week were categorized as inactive. Respondents who engaged in high-impact physical activity for 20 minutes at least 3 times a week or in moderate-impact physical activity for 30 minutes at least 5 times a week were categorized as active. Participants who exercised regularly but not enough to qualify as active according to the strength, duration, and frequency standards of our study were classified as less active.

The main independent variables were the health behaviors of each respondent's partner, age, and whether the respondent was a housewife. For smoking, eating salty foods, and physical activity, we used the same categories outlined above. Since the WHO definition of drinking habits differs by sex, excessive drinking by partners was defined as consuming over $40 \mathrm{~g}$ of pure alcohol at once [17]. Age was categorized as follows: $19-29,30-49,50-64$, and $\geq 65$ years old. In the KCHS, a housewife is defined as a married woman who manages her own household as her principal occupation. We considered respondents who chose the "housewife" category for the occupation item as housewives, and the others were regarded as non-housewives.

We divided the metropolitan provinces and non-metropolitan provinces by the region in which the respondent lived. South Korea (hereafter Korea) is divided into 7 metropolitan and 9 non-metropolitan provinces. When a city's population 
nears 1 million, the Korean government considers re-classifying it as a metropolitan province. Currently, all 7 Korean metropolitan provinces have a population of more than 1 million.

In terms of occupation, we followed the international standard classification of occupations [18]. Managers, professionals, technicians, and associate professionals were classified as white-collar. Clerical support workers; services and sales workers; skilled agricultural, forestry, and fishery workers; craft and related trades workers; plant and machine operators and assemblers; and those who engaged in elementary occupations were classified as blue-collar. The category of "other" included students, unemployed individuals, housewives, and those in the Armed Forces. Hypertension, diabetes mellitus, and hyperlipidemia were considered present only when diagnosed by a physician. Adjusted monthly household income was calculated from the median value of the range of the corresponding survey answer selected by the respondent, divided by the square root of the number of family members [19].

We used chi-square analysis for the categorical variables. The main statistical analysis was conducted with multivariate logistic regression modeling. We calculated the odds ratios (ORs) and 95\% confidence intervals (Cis) for the partners' corresponding health behaviors: smoking, excessive drinking, eating salty foods, and an inactive lifestyle. In the multiple lo- gistic regression analysis, the reference group was the respondents whose partners did not have risky health behaviors. We treated the health habits as binary categories: 1) current smoking vs. other responses, 2) excessive drinking vs. other responses, 3) eating salty foods vs. other responses, and 4) inactive lifestyle vs. other responses. Potential confounding variables included in the regression analysis included metropolitan status, occupation, household income (upper $50 \%$ vs. lower $50 \%$ ), and disease status with regard to hypertension, diabetes mellitus, and hyperlipidemia. In the overall analysis, we included age as a covariate, and the interaction between the partner's health behavior and age group was assessed. We next performed an age-stratified logistic regression analysis. Concordance between participants' and partners' risk behaviors was respectively modeled. Finally, we tested whether interactions were present between age and the partners' risk behaviors to assess whether the concordance varied by age group. The following regression models were used for these analyses:

Crude model: $Y-X$

Adjusted model: $Y-X+Z$

Interaction model: $Y-X+$ Age $+Z+X \times$ Age

, where $Y$ is the participant's risky health behavior, $X$ is whether the partner engaged in that risky health behavior,

Table 1. Socio-demographic characteristics and chronic disease status of Korean women aged 19 or over with partners

\begin{tabular}{|c|c|c|c|c|c|c|}
\hline & Total & $19-29 y$ & $30-49 y$ & $50-64$ y & $\geq 65 y$ & $p$-value \\
\hline Total & $64971(100.0)$ & $1804(2.8)$ & $26165(40.3)$ & $23026(35.4)$ & $13976(21.5)$ & \\
\hline Region & & & & & & $<0.01$ \\
\hline Urban & $18012(27.7)$ & $564(31.3)$ & 8325 (31.8) & $6278(27.3)$ & $2845(20.4)$ & \\
\hline Rural & $46959(72.3)$ & $1240(68.7)$ & $17840(68.2)$ & $16748(72.7)$ & $11131(79.6)$ & \\
\hline Occupation & & & & & & $<0.01$ \\
\hline White-collar & 10409 (16.0) & $482(26.7)$ & $8109(31.0)$ & $1728(7.5)$ & $90(0.6)$ & \\
\hline Blue-collar & 26503 (40.8) & $300(16.6)$ & 7952 (30.4) & $12671(55.0)$ & $5580(39.9)$ & \\
\hline Housewife & $26580(40.9)$ & $988(54.8)$ & $9959(38.1)$ & $8327(36.2)$ & $7306(52.3)$ & \\
\hline Others & $1479(2.3)$ & $34(1.9)$ & $145(0.6)$ & $300(1.3)$ & $1000(7.2)$ & \\
\hline Adjusted household income (Korean won) & & & & & & $<0.01$ \\
\hline Quartile 1 (lowest) & 14487 (22.3) & $209(11.6)$ & $1943(7.4)$ & 4293 (18.6) & 8042 (57.5) & \\
\hline Quartile 2 & 15911 (24.5) & $517(28.7)$ & $5804(22.2)$ & $5957(25.9)$ & $3633(26.0)$ & \\
\hline Quartile 3 & 17071 (26.3) & $460(25.5)$ & 9425 (36.0) & $5900(25.6)$ & $1286(9.2)$ & \\
\hline Quartile 4 (highest) & $17010(26.2)$ & $606(33.6)$ & 8798 (33.6) & $6674(29.0)$ & $932(6.7)$ & \\
\hline Missing & $492(0.8)$ & $12(0.7)$ & $195(0.7)$ & $202(0.9)$ & $83(0.6)$ & \\
\hline \multicolumn{7}{|l|}{ Diagnosis of chronic disease } \\
\hline Hypertension & 14892 (22.9) & $15(0.8)$ & $1200(4.6)$ & $6201(26.9)$ & 7476 (53.5) & $<0.01$ \\
\hline Diabetes mellitus & $5385(8.3)$ & $9(0.5)$ & $520(2.0)$ & $2140(9.3)$ & 2716 (19.4) & $<0.01$ \\
\hline Hyperlipidemia & $9965(15.3)$ & $15(0.8)$ & $1225(4.7)$ & $5174(22.5)$ & $3551(25.4)$ & $<0.01$ \\
\hline
\end{tabular}

Values are presented as number (\%). 
and $\mathrm{Z}$ indicates potential confounding factors such as age (only in the overall models), occupation, household income, and past medical history (hypertension, diabetes mellitus, hyperlipidemia).

Additional analyses were similarly conducted to assess whether being a housewife affected the influence exerted by one's partner.

This survey was designed to include a mean of 900 respondents from each county, regardless of the county's population. Hence, we applied individual weights in the analysis to correct for the target population. Data were analyzed using SAS version 9.4 (SAS Institute Inc., Cary, NC, USA).

\section{RESULTS}

In 2015, the KCHS included 228588 participants, of whom 155756 reported having a partner. We excluded 13897 individuals who were included in a household with more than 1 couple. We were able to match 129942 of the 141859 subjects (64 971 couples) by household ID number and sex. We

Table 2. Health behaviors of Korean women aged 19 or over and their partners ( $N=64971)$

\begin{tabular}{|c|c|c|c|c|c|c|}
\hline & Total & $19-29 y$ & $30-49 y$ & $50-64 y$ & $\geq 65 y$ & $p$-value \\
\hline \multicolumn{7}{|c|}{ Health behaviors of women } \\
\hline Smoking status & & & & & & $<0.01$ \\
\hline Smoker & $1095(1.7)$ & $78(4.3)$ & $504(1.9)$ & $379(1.6)$ & $134(1.0)$ & \\
\hline Ex-smoker & $1191(1.8)$ & $114(6.3)$ & $644(2.5)$ & $245(1.1)$ & $188(1.3)$ & \\
\hline Non-smoker & 62685 (96.5) & $1612(89.4)$ & 25017 (95.6) & 22402 (97.3) & 13654 (97.7) & \\
\hline Alcohol consumption & & & & & & $<0.01$ \\
\hline Excessive drinking & $16429(25.3)$ & $734(40.7)$ & 10267 (39.2) & $4712(20.5)$ & $716(5.1)$ & \\
\hline Moderate drinking & 23266 (35.8) & $573(31.8)$ & 10039 (38.4) & $8783(38.1)$ & $3871(27.7)$ & \\
\hline No drinking & $25276(38.9)$ & $497(27.5)$ & $5859(22.4)$ & $9531(41.4)$ & $9389(67.2)$ & \\
\hline Dietary habits & & & & & & $<0.01$ \\
\hline Eats salty foods & $12308(18.9)$ & $509(28.2)$ & $4688(17.9)$ & $3836(16.7)$ & $3275(23.4)$ & \\
\hline Eats normally & $35646(54.9)$ & $848(47.0)$ & $14490(55.4)$ & $12977(56.4)$ & $7331(52.5)$ & \\
\hline Eats less salty foods & $17017(26.2)$ & 447 (24.8) & $6987(26.7)$ & $6213(27.0)$ & $3370(24.1)$ & \\
\hline Physical activity & & & & & & $<0.01$ \\
\hline Inactive & $37170(57.2)$ & $1130(62.6)$ & $14335(54.8)$ & $12681(55.1)$ & $9024(64.6)$ & \\
\hline Less active & $13501(20.8)$ & $381(21.1)$ & $6288(24.0)$ & $4698(20.4)$ & $2134(15.3)$ & \\
\hline Active & $14300(22.0)$ & $293(16.2)$ & $5542(21.2)$ & $5647(24.5)$ & $2818(20.2)$ & \\
\hline \multicolumn{7}{|c|}{ Health behaviors of partners } \\
\hline Smoking status & & & & & & $<0.01$ \\
\hline Smoker & 21989 (33.8) & $838(46.5)$ & $11850(45.3)$ & $6860(29.8)$ & $2441(17.5)$ & \\
\hline Ex-smoker & $28793(44.3)$ & $454(25.2)$ & $8479(32.4)$ & 11439 (49.7) & $8421(60.3)$ & \\
\hline Non-smoker & 14189 (21.8) & $512(28.4)$ & $5836(22.3)$ & $4727(20.5)$ & $3114(22.3)$ & \\
\hline Alcohol consumption & & & & & & $<0.01$ \\
\hline Excessive drinking & 30239 (46.5) & $1190(66.0)$ & 16662 (63.7) & $9962(43.3)$ & $2425(17.4)$ & \\
\hline Moderate drinking & $21075(32.4)$ & $506(28.0)$ & $6976(26.7)$ & $7903(34.3)$ & $5690(40.7)$ & \\
\hline No drinking & $13657(21.0)$ & $108(6.0)$ & $2527(9.7)$ & $5161(22.4)$ & $5861(41.9)$ & \\
\hline Dietary habits & & & & & & $<0.01$ \\
\hline Eats salty foods & $18353(28.2)$ & $764(42.4)$ & $7561(28.9)$ & $5692(24.7)$ & $4336(31.0)$ & \\
\hline Eats normally & $31145(47.9)$ & $786(43.6)$ & $13074(50.0)$ & $11147(48.4)$ & $6138(43.9)$ & \\
\hline Eats less salty foods & $15473(23.8$ & $254(14.1)$ & $5530(21.1)$ & $6187(26.9)$ & $3502(25.1)$ & \\
\hline Physical activity & & & & & & $<0.01$ \\
\hline Inactive & 31468 (48.4) & 714 (39.6) & $10833(41.4)$ & 11073 (48.1) & 8848 (63.3) & \\
\hline Less active & $15626(24.1)$ & $549(30.4)$ & 7889 (30.2) & $5173(22.5)$ & $2015(14.4)$ & \\
\hline Active & $17877(27.5)$ & $541(30.0)$ & $7443(28.4)$ & $6780(29.4)$ & $3113(22.3)$ & \\
\hline
\end{tabular}

Values are presented as number (\%). 
ultimately included only the 64971 women older than 18 years of age who were matched with their husbands.

Table 1 shows the demographic characteristics of the study population. Older women more frequently lived in rural regions, had a lower income, and had chronic diseases. Women in the youngest and the oldest groups were more likely to be housewives than those in the other age groups. Table 2 presents the health behaviors of the partners and the participants. The partners engaged in more high-risk behaviors than did the women in terms of smoking, excessive drinking, and eating salty food. However, physical inactivity was higher for the women than for their partners. Smoking and excessive drinking were highest among the younger women and decreased as both spouses aged. The proportion of both spouses reporting physical inactivity was highest in the oldest age group.

The results of the logistic regression analysis of the correlations of the health behaviors of participants and partners are shown in Table 3. Smoking (adjusted OR [aOR], 4.65; 95\% Cl, 3.93 to 5.49) had the strongest intra-couple association among the 4 health behaviors. Regarding smoking, elderly members of a couple showed the strongest association, even though they had the lowest smoking rate $(\mathrm{aOR}, 8.15 ; 95 \% \mathrm{Cl}$, 5.50 to 12.09). Regarding excessive drinking, the younger age groups (aOR, 1.90; $95 \% \mathrm{Cl}, 1.64$ to 2.20 for $19-29$ years and AOR, $1.94 ; 95 \% \mathrm{Cl}, 1.82$ to 2.06 for $30-49$ years) showed strong intra-couple associations. Regarding eating salty foods and an

Table 3. Results of logistic regression analysis of the impact of partners' risky health behaviors on risky health behaviors among Korean women aged 19 or over

\begin{tabular}{|c|c|c|c|c|c|c|}
\hline Variables & Age (y) & Total (n) & $\begin{array}{c}\text { Participant's } \\
\text { behavior, n (\%) }\end{array}$ & $\begin{array}{l}\text { Crude OR } \\
(95 \% \mathrm{CI})^{1}\end{array}$ & $\begin{array}{c}\text { Adjusted OR } \\
(95 \% \mathrm{CI})^{1}\end{array}$ & $\begin{array}{l}p \text {-value for } \\
\text { interaction }\end{array}$ \\
\hline \multicolumn{7}{|l|}{ Smoking } \\
\hline Overall & $<19$ & 64971 & $1095(1.7)$ & $5.07(4.32,5.95)$ & $4.65(3.93,5.49)$ & 0.01 \\
\hline \multirow[t]{4}{*}{ Stratified } & $19-29$ & 1804 & $78(4.3)$ & $5.47(4.44,6.72)$ & $5.38(4.20,6.89)$ & \\
\hline & $30-49$ & 26165 & $504(1.9)$ & $5.44(4.27,6.94)$ & $5.20(4.06,6.65)$ & \\
\hline & $50-64$ & 23026 & $379(1.6)$ & $3.51(2.76,4.47)$ & $3.45(2.70,4.41)$ & \\
\hline & $\geq 65$ & 13976 & $134(1.0)$ & $7.86(5.35,11.53)$ & $8.15(5.50,12.09)$ & \\
\hline \multicolumn{7}{|c|}{ Excessive drinking } \\
\hline Overall & $<19$ & 64971 & $16429(25.3)$ & $2.58(2.47,2.70)$ & $1.89(1.80,1.98)$ & 0.55 \\
\hline \multirow[t]{4}{*}{ Stratified } & $19-29$ & 1804 & $734(40.7)$ & $1.88(1.64,2.17)$ & $1.90(1.64,2.20)$ & \\
\hline & $30-49$ & 26165 & 10267 (39.2) & $1.94(1.82,2.06)$ & $1.94(1.82,2.06)$ & \\
\hline & $50-64$ & 23026 & 4712 (20.5) & $1.85(1.71,2.00)$ & $1.81(1.67,1.96)$ & \\
\hline & $\geq 65$ & 13976 & $716(5.1)$ & $1.79(1.50,2.15)$ & $1.77(1.48,2.12)$ & \\
\hline \multicolumn{7}{|c|}{ Eats salty food } \\
\hline Overall & $<19$ & 64971 & 12308 (18.9) & $2.56(2.43,2.70)$ & $2.48(2.36,2.62)$ & $<0.01$ \\
\hline \multirow[t]{4}{*}{ Stratified } & $19-29$ & 1804 & $509(28.2)$ & $2.18(1.91,2.49)$ & $2.22(1.94,2.54)$ & \\
\hline & $30-49$ & 26165 & $4688(17.9)$ & $2.23(2.07,2.40)$ & $2.23(2.07,2.40)$ & \\
\hline & $50-64$ & 23026 & $3836(16.7)$ & $2.70(2.48,2.95)$ & $2.64(2.42,2.88)$ & \\
\hline & $\geq 65$ & 13976 & $3275(23.4)$ & $3.33(3.04,3.64)$ & $3.29(3.00,3.59)$ & \\
\hline \multicolumn{7}{|c|}{ Inactive lifestyle } \\
\hline Overall & $<19$ & 64971 & 37170 (57.2) & $2.66(2.56,2.77)$ & $2.56(2.45,2.66)$ & $<0.01$ \\
\hline \multirow[t]{4}{*}{ Stratified } & $19-29$ & 1804 & $1130(62.6)$ & $2.29(2.01,2.59)$ & $2.29(2.01,2.60)$ & \\
\hline & $30-49$ & 26165 & 14335 (54.8) & $2.27(2.14,2.41)$ & $2.24(2.12,2.37)$ & \\
\hline & $50-64$ & 23026 & 12681 (55.1) & $2.88(2.70,3.08)$ & $2.80(2.63,2.99)$ & \\
\hline & $\geq 65$ & 13976 & 9024 (64.6) & $3.70(3.41,4.00)$ & $3.53(3.26,3.83)$ & \\
\hline
\end{tabular}

$\mathrm{OR}$, odds ratio; $\mathrm{Cl}$, confidence interval.

'Crude model: $Y-X$, adjusted model: $Y-X+Z$, where $Y=$ the participant's risky health behavior, $X=$ whether the partner had the risky health behavior, and $Z=$ potential confounding factors including age (only in the overall models), occupation, household income, and past medical history (hypertension, diabetes mellitus, hyperlipidemia). See the Methods section for more details.

${ }^{2} p$-values were obtained from the overall models for the interaction between age and the respective health behavior. Interaction model: $Y-X+A g e+Z+X \times A g e$, where $Y=$ the participant's risky health behavior, $X=$ whether the partner had the risky health behavior, Age $=$ the participant's age group, $Z=$ potential confounding factors including occupation, household income, and past medical history (hypertension, diabetes mellitus, hyperlipidemia), and $X \times A g e=$ the interaction between age and the respective health behavior. 
inactive life style, the strength of the intra-couple associations increased as the age of the members increased. When we tested $p$ for interaction between age group and each health behavior of the partners, we found significant interactions for smoking, eating salty food, and an inactive lifestyle.

Table 4 compares the data from housewives with those from non-housewives. Table 4 shows that, with regard to eating salty food, the intra-couple associations in housewives were stronger than those in non-housewives; this was true for all age groups. Among elderly couples, the intra-couple correlations for smoking were stronger in housewives than non- housewives. Among couples aged 30-49 years, the intra-couple correlations for excessive drinking were stronger for nonhousewives than housewives. In the other age groups, intracouple correlations in housewives for smoking and excessive drinking were stronger than those in non-housewives. However, regardless of age group, the weakest correlation between the behaviors of housewives and those of their partners was for leading an inactive lifestyle. When we tested $p$ for interaction between whether the participants was a housewife and each health behavior of their partners, we only found a significant interaction for eating salty food.

Table 4. Results of logistic regression analysis of the impact of partners' risky health behaviors on the risky health behaviors among Korean housewives $(N=26580)$ and non-housewives $(N=37747)$ aged 19 or over

\begin{tabular}{|c|c|c|c|c|c|c|c|c|}
\hline \multirow[b]{2}{*}{ Variables } & \multirow[b]{2}{*}{ Age (y) } & \multicolumn{3}{|c|}{ Housewives } & \multicolumn{3}{|c|}{ Non-housewives } & \multirow{2}{*}{$\begin{array}{c}p \text {-value for } \\
\text { interaction }\end{array}$} \\
\hline & & Total (n) & $\begin{array}{c}\text { Participant's } \\
\text { behavior, n (\%) }\end{array}$ & $\begin{array}{l}\text { Adjusted OR } \\
(95 \% \mathrm{CI})^{1}\end{array}$ & Total (n) & $\begin{array}{c}\text { Participant's } \\
\text { behavior, n (\%) }\end{array}$ & $\begin{array}{l}\text { Adjusted OR } \\
(95 \% \mathrm{Cl})^{1}\end{array}$ & \\
\hline \multicolumn{9}{|l|}{ Smoking } \\
\hline Overall & $<19$ & 26580 & $451(1.7)$ & $5.60(4.43,7.07)$ & 37747 & $644(1.7)$ & $4.28(3.45,5.31)$ & 0.19 \\
\hline \multirow[t]{4}{*}{ Stratified } & $19-29$ & 988 & $32(3.2)$ & $6.67(4.38,10.16)$ & 770 & $46(6.0)$ & $4.62(3.96,5.38)$ & 0.21 \\
\hline & $30-49$ & 9959 & $189(1.9)$ & $6.71(4.66,9.66)$ & 15891 & $315(2.0)$ & $4.76(3.61,6.29)$ & 0.17 \\
\hline & $50-64$ & 8327 & $157(1.9)$ & $4.16(3.04,5.68)$ & 14477 & $222(1.5)$ & $2.27(2.12,2.44)$ & 0.19 \\
\hline & $\geq 65$ & 7306 & $73(1.0)$ & $6.84(3.99,11.72)$ & 6609 & $61(0.9)$ & $10.39(7.06,15.29)$ & 0.37 \\
\hline \multicolumn{9}{|c|}{ Excessive drinking } \\
\hline Overall & $<19$ & 26580 & $5484(20.6)$ & $1.91(1.77,2.06)$ & 37747 & $10945(29.0)$ & $1.88(1.77,1.99)$ & 0.68 \\
\hline \multirow[t]{4}{*}{ Stratified } & $19-29$ & 988 & $353(35.7)$ & $2.13(1.80,2.53)$ & 770 & $381(49.5)$ & $1.74(1.53,1.98)$ & 0.18 \\
\hline & $30-49$ & 9959 & $3283(33.0)$ & $1.86(1.69,2.04)$ & 15891 & $6984(43.9)$ & $1.99(1.85,2.15)$ & 0.26 \\
\hline & $50-64$ & 8327 & $1475(17.7)$ & $1.99(1.78,2.23)$ & 14477 & 3237 (22.4) & $1.70(1.56,1.86)$ & 0.06 \\
\hline & $\geq 65$ & 7306 & $373(5.1)$ & $1.82(1.44,2.30)$ & 6609 & $343(5.2)$ & $1.70(1.45,2.00)$ & 0.87 \\
\hline \multicolumn{9}{|c|}{ Eats salty food } \\
\hline Overall & $<19$ & 26580 & 4858 (18.3) & $2.73(2.53,2.95)$ & 37747 & 7450 (19.7) & $2.30(2.15,2.46)$ & $<0.01$ \\
\hline \multirow[t]{4}{*}{ Stratified } & $19-29$ & 988 & $257(26.0)$ & $2.45(2.11,2.85)$ & 770 & 252 (32.7) & $2.10(1.85,2.39)$ & 0.16 \\
\hline & $30-49$ & 9959 & $1706(17.1)$ & $2.37(2.13,2.65)$ & 15891 & 2982 (18.8) & $2.13(1.94,2.34)$ & 0.14 \\
\hline & $50-64$ & 8327 & $1238(14.9)$ & $2.97(2.61,3.37)$ & 14477 & 2598 (17.9) & $2.44(2.22,2.70)$ & 0.02 \\
\hline & $\geq 65$ & 7306 & $1657(22.7)$ & $3.39(3.03,3.78)$ & 6609 & $1618(24.5)$ & $3.13(2.81,3.50)$ & 0.42 \\
\hline \multicolumn{9}{|c|}{ Inactive lifestyle } \\
\hline Overall & $<19$ & 26580 & $16166(60.8)$ & $2.46(2.31,2.61)$ & 37747 & 21004 (55.6) & $2.63(2.49,2.78)$ & 0.48 \\
\hline \multirow[t]{4}{*}{ Stratified } & $19-29$ & 988 & $657(66.5)$ & $2.20(1.90,2.56)$ & 770 & $473(61.4)$ & $2.46(2.16,2.81)$ & 0.49 \\
\hline & $30-49$ & 9959 & 5553 (55.8) & $2.20(2.02,2.39)$ & 15891 & 8782 (55.3) & $2.27(2.12,2.44)$ & 0.74 \\
\hline & $50-64$ & 8327 & $4751(57.1)$ & $2.64(2.41,2.89)$ & 14477 & 7930 (54.8) & $2.94(2.72,3.19)$ & 0.23 \\
\hline & $\geq 65$ & 7306 & 5205 (71.2) & $3.00(2.71,3.32)$ & 6609 & 3819 (57.8) & $4.90(4.46,5.38)$ & $<0.01$ \\
\hline
\end{tabular}

$\mathrm{OR}$, odds ratio; $\mathrm{Cl}$, confidence interval.

${ }^{1}$ Adjusted model: $Y-X+Z$, where $Y=$ the participant's risky health behavior, $X=$ whether the partner had the risky health behavior, $Z=$ potential confounding factors, including age (only in the overall models), occupation (only in the non-housewives model), household income, past medical history (hypertension, diabetes mellitus, hyperlipidemia). See the Methods section for more details.

${ }^{2} p$-values were obtained using the data including both housewives and non-housewives, from each model for the interaction between the housewife status and the respective health behavior. Interaction model: $Y-X+H+Z+X \times H$, where $Y=$ the participant's risky health behavior, $X=$ whether the partner had the risky health behavior, $\mathrm{H}$ =housewife status, $\mathrm{Z}=$ potential confounding factors including occupation, household income, and past medical history (hypertension, diabetes mellitus, hyperlipidemia), and $\mathrm{X} \times \mathrm{H}=$ the interaction between housewife status and the respective health behavior. 


\section{DISCUSSION}

We found positive correlations between the health behaviors of woman participants and those of their partners in 4 domains. The effect size varied according to age group and whether the participant was a housewife.

Our finding that all 4 health behaviors showed positive intra-couple correlations is consistent with previous studies [8,9,20-22]. This can be explained by several factors. First, people generally meet and marry an individual who shares similar life patterns and preferences. Second, partners have mutual direct or indirect social control of each other's health behaviors [5]. Indeed, one member of a couple starting to engage in a new behavior can act as the initial motivation for the other to do so, regardless of the health effects of the behavior. Alternatively, when one member of a couple does not engage in a risky behavior that the other does engage in, the former can influence the latter to stop.

This study showed that smoking had the highest intra-couple correlation among the 4 health behaviors. Smoking must be a significant target of public health policy because smoking by both members of a couple constitutes a direct and indirect hazard [23].

Interestingly, the age groups most likely to engage in risky health behaviors also showed strong intra-couple correlations. The rates of smoking and excessive drinking were highest in the youngest groups, and that of leading an inactive lifestyle was highest in the oldest group. Similarly, the intra-couple correlations for smoking and excessive drinking were strongest in the youngest groups and those for leading an inactive lifestyle were elevated in the oldest group.

We hypothesized that the magnitude of the correlations would differ significantly by age group. Although the intracouple associations for excessive alcohol consumption did not differ significantly by age, we did find age differences in the rates of smoking, excessive drinking, and leading an inactive lifestyle. Both the age-cohort effect and social changes related to gender roles may be relevant in this regard. The oldest Korean generation grew up in a patriarchal culture [24], in which married women were far more likely than their younger counterparts to cook for their partners and to adjust their cooking styles to fit their partners' tastes. This trend is changing, and many young women do not prepare meals according to their partners' standards or adjust their cooking styles to satisfy their partners [25]. This may explain why the behaviors of older (vs. younger) women were more strongly correlated with those of their partners. Furthermore, most people engage in physical activity in their leisure time, and elderly individuals are more likely to spend their leisure time with family. Thus, it is not surprising that the intra-couple correlations for leading an inactive lifestyle would be stronger in elderly couples.

We hypothesized that housewives (vs. non-housewives) would have stronger concordance with risky health behaviors of their partners. However, only eating salty food had a significantly strong concordance. This is probably because of the importance of food preparation as part of the role of the housewife. Regarding leading an inactive lifestyle, we found that the intra-couple correlations of couples with housewives were weaker than those of couples with non-housewives over 64 years old. Many public and private physical exercise programs are available during the day, and many housewives participate in these programs with neighbors, regardless of the interest of their partners. In contrast, because many non-housewives work during the day, their leisure time is more closely matched to that of their partners. For this reason, unlike other health behaviors, couples with non-housewives were more likely to lead an inactive lifestyle jointly. For smoking, we determined the absolute difference between the 2 groups' ORs. However, it was not significant. We assume that this was due to the small sample size.

Due to the possibility of an age-confounding effect in the oldest group, we performed an additional analysis with narrower age categories. The original age range of the oldest group was 65 to 93 years. Thus, we divided this group into 3 subgroups: subgroup 1, 64-69 years old; subgroup 2, 70-74 years old; and subgroup $3, \geq 75$ years old. The results of this analysis are presented in Supplemental Table 1. Stratification by the narrower age categorization revealed several differences in the 4 health behaviors. In particular, excessive drinking was negatively correlated with spousal health behaviors in subgroup 3 . When we analyzed men of the same age ( $\geq 75$ years old), the men had 1.45 times the risk of drinking excessively $(95 \% \mathrm{Cl}, 1.40$ to 1.50$)$ than did the women. Why did only women older than 74 years of age have a lower risk of excessive drinking when their partners drank excessively? In previous generations, many women married older men. Thus, the average age of the partners of the women in subgroup 3 was 80.3 years (standard deviation [SD], 4.23 years), whereas the average age of the partners in the same-aged men was 74.6 
years old (SD, 4.87 years). In this context, it is not surprising that the comparatively younger women were more able than their older partners to observe the physical harm associated with excessive drinking by the latter.

We can use our results to develop new public health messages. Based on the fact that high-risk groups had higher intra-couple correlations, couple-level interventions should be considered when planning public health initiatives. This is especially true for smoking, which had the highest intra-couple correlation in this study, because smoking is more harmful when both members of a couple engage in this behavior. Moreover, because each generation has unique characteristics, we must also consider the age of the target population.

This study has several limitations. First, we assumed that the intra-couple correlations would be associated with the strength of the couple's relationship. However, we could not investigate that factor. Accordingly, this study was based on the assumption that all couples had similar relationships. Second, we could not separate the husband's effect on the wife from the wife's effect on the husband. Third, as data on each health behavior were collected through a questionnaire, there is a possibility of information bias. However, this survey used a structured questionnaire administered by trained interviewers in one-on-one interviews. This approach may have mitigated the possibility of information bias.

We found positive intra-couple correlations for smoking, excessive drinking, eating salty foods, and leading an inactive lifestyle. The correlation was strongest for smoking. For the oldest age group, however, the correlations for eating salty foods and leading an inactive lifestyle were higher. These results underscore the importance of identifying the shared factors leading to high-risk health behaviors and of considering simultaneous interventions for both members of a couple.

\section{CONFLICT OF INTEREST}

The authors have no conflicts of interest associated with the material presented in this paper.

\section{ORCID}

Seungmin Jeong http://orcid.org/0000-0002-5409-3324

Sung-il Cho http://orcid.org/0000-0003-4085-1494

\section{REFERENCES}

1. Li K, Hüsing A, Kaaks R. Lifestyle risk factors and residual life expectancy at age 40: a German cohort study. BMC Med 2014; 12:59.

2. Selmer RM, Kristiansen IS, Haglerod A, Graff-Iversen S, Larsen $\mathrm{HK}$, Meyer HE, et al. Cost and health consequences of reducing the population intake of salt. J Epidemiol Community Health 2000;54(9):697-702.

3. Lee IM, Shiroma EJ, Lobelo F, Puska P, Blair SN, Katzmarzyk PT, et al. Effect of physical inactivity on major non-communicable diseases worldwide: an analysis of burden of disease and life expectancy. Lancet 2012;380(9838):219-229.

4. Tay L, Tan K, Diener E, Gonzalez E. Social relations, health behaviors, and health outcomes: a survey and synthesis. Appl Psychol Health Well Being 2013;5(1):28-78.

5. Umberson D. Family status and health behaviors: social control as a dimension of social integration. J Health Soc Behav 1987;28(3):306-319.

6. Zhang J, Wu L. Cigarette smoking and alcohol consumption among Chinese older adults: do living arrangements matter? Int J Environ Res Public Health 2015;12(3):2411-2436.

7. Matsuzuki $H$, Muto T, Haruyama Y. School children's salt intake is correlated with salty taste preference assessed by their mothers. Tohoku J Exp Med 2008;215(1):71-77.

8. Jurj AL, Wen W, Li HL, Zheng W, Yang G, Xiang YB, et al. Spousal correlations for lifestyle factors and selected diseases in Chinese couples. Ann Epidemiol 2006;16(4):285-291.

9. Meyler D, Stimpson JP, Peek MK. Health concordance within couples: a systematic review. Soc Sci Med 2007;64(11):22972310.

10. Schierberl Scherr AE, McClure Brenchley KJ, Gorin AA. Examining a ripple effect: do spouses' behavior changes predict each other's weight loss? J Obes 2013;2013:297268.

11. Margolis R, Wright L. Better off alone than with a smoker: the influence of partner's smoking behavior in later life. J Gerontol B Psychol Sci Soc Sci 2016;71(4):687-697.

12. Windle $M$, Windle RC. A prospective study of alcohol use among middle-aged adults and marital partner influences on drinking. J Stud Alcohol Drugs 2014;75(4):546-556.

13. Ask H, Rognmo K, Torvik FA, Røysamb E, Tambs K. Non-random mating and convergence over time for alcohol consumption, smoking, and exercise: the Nord-Trøndelag Health Study. Behav Genet 2012;42(3):354-365.

14. Kang YW, Ko YS, Kim YJ, Sung KM, Kim HJ, Choi HY, et al. Korea 
Community Health Survey data profiles. Osong Public Health Res Perspect 2015;6(3):211-217.

15. Kim H, Lee K, Chang S, Kang G, Tak Y, Lee M, et al. Factors affecting the validity of self-reported data on health services from the Community Health Survey in Korea. Yonsei Med J 2013;54(4):1040-1048.

16. Kim SJ, Han JA, Kim YH, Choi BY, Kim SY, Lee HJ, et al. Test-retest reliability of health behavior items in the Community Health Survey in South Korea. Epidemiol Health 2015;37: e2015045.

17. Ezzati M, Lopez AD, Rodgers A, Murray CJ. Comparative quantification of health risks: global and regional burden of disease attributable to selected major risk factors; 2004 [cited 2018 Jan 10]. Available from: http://apps.who.int/iris/bitstream/10665/42792/1/9241580348_eng_Volume1.pdf.

18. Ganzeboom HB. International standard classification of occupations ISCO-08 with ISEI-08 scores; 2010 [cited 208 Jan 10]. Available from: http://www.harryganzeboom.nl/isco08/ isco08_with_isei.pdf.

19. Aaberge R, Melby I. The sensitivity of income inequality to choice of equivalence scales. Rev Income Wealth 1998;44(4): 565-569.

20. Jackson SE, Steptoe A, Wardle J. The influence of partner's behavior on health behavior change: the English Longitudinal Study of Ageing. JAMA Intern Med 2015;175(3):385-392.

21. Reynolds CA, Barlow T, Pedersen NL. Alcohol, tobacco and caffeine use: spouse similarity processes. Behav Genet 2006; 36(2):201-215.

22. Wilson SE. The health capital of families: an investigation of the inter-spousal correlation in health status. Soc Sci Med 2002;55(7):1157-1172.

23. Ranby KW, Lewis MA, Toll BA, Rohrbaugh MJ, Lipkus IM. Perceptions of smoking-related risk and worry among dualsmoker couples. Nicotine Tob Res 2013;15(3):734-738.

24. Kim JY, Emery C. Marital power, conflict, norm consensus, and marital violence in a nationally representative sample of Korean couples. J Interpers Violence 2003;18(2):197-219.

25. Kyung-Sup C, Min-Young S. The stranded individualizer under compressed modernity: South Korean women in individualization without individualism. Br J Sociol 2010;61 (3):539-564. 